\title{
MILKMETER BASED ON ELECTRIC CAPACITIVE FLOW SENSOR
}

\author{
Vitaliy Tkach ${ }^{1}$, Vasyl Achkevych ${ }^{2}$, Viacheslav Bratishko², Oksana Achkevych ${ }^{2}$ \\ ${ }^{1}$ Institute for Agricultural Engineering and Electrification, Ukraine; ${ }^{2}$ National University of Life and \\ Environmental Sciences of Ukraine, Ukraine \\ 3993980@gmail.com, achkevychv@gmail.com, vbratishko@gmail.com, achkevych@gmail.com
}

\begin{abstract}
The research concerns the creation of effective monitoring of the intensity of milk production and accounting for individual milk yield. The article presents the results of theoretical and experimental studies of a capacitive flow sensor and a milk meter. A mathematical model is developed, and dependences are obtained, which reveal the relationship between the signal of the capacitive flow sensor, its design parameters and the parameters of the pulsating milk flow (volume and flow speed). Within the conditions of this mathematical model, the result of calculating the milk does not depend on the characteristics of the capacitive flow sensor and the electrical properties of milk. Based on the obtained dependences, a signal processing algorithm and appropriate software for determining individual milk yield and milk flow through the milk supply hose of the milking machine have been developed. A prototype of a milk meter based on a capacitive flow sensor is made. Production inspection of the meter at the facilities with a stable milk pipeline and laboratory studies of its operation as part of the installation for milking cows were carried out. The average measurement error when milking low-yielding livestock in production conditions was $5.7 \%$. During laboratory tests, a systematic deviation of the meter model readings to the smaller side was recorded, which is due to the use of the lower milk line to simulate the milking parlour. Control measurements in production conditions were carried out on two tie stall farms. Each farm had 100 animals. The total number of control milking was 30 repetitions. There is also a systematic dependence of meter readings on the intensity of the milk production. These systematic deviations are corrected by the introduction of a correction factor, which, when changing the intensity of milk production from $1.6 \times 10^{-5} \mathrm{~m}^{3} \cdot \mathrm{s}^{-1}$ to $6.6 \times 10^{-5} \mathrm{~m}^{3} \cdot \mathrm{s}^{-}$ ${ }^{1}$, changes from 1.2 to 1.7 , respectively.
\end{abstract}

Keywords: milking, milk flow, electric capacitive sensor.

\section{Introduction}

In precision livestock farming, one of the key components of the technical support for the milk production process is the means of operational monitoring of milk production intensity, which are the basis for adaptive milking systems, means of monitoring the physiological condition of cows and individual milk production [1-3]. Volumetric operating principle mechanical meters (bucket and float type) are widely used to determine individual productivity of cows. Their disadvantages are the low level of sampling flow measurements, significant measurement error at high milk yield, low mobility and difficult integration into automatic milking. The means of monitoring the intensity of milk flow presented on the market have a number of disadvantages, including low accuracy of the measurements. The market leaders in such devices are optical (infrared) sensors, such as FFS-30 manufactured by SCR [4]. BECO has developed a sensor of milk flow intensity using the capacitive principle of action [5]. The same type of devices includes flow sensors of milk production intensity from Panazoo [6].

One of the simplest in design is a capacitive sensor, which also allows to assess the conductivity of milk and its temperature without contact with the measured medium. However, there is a significant difference in the signal of the capacitive sensor for different physical manifestations of liquids [7-9] (solid medium, surface film, foam). Heterogeneous properties of milk obtained in different periods and from different animals $[7 ; 10-12]$ and the lack of appropriate algorithms for signal interpretation prevent the use of capacitive sensors to monitor the intensity of milk production and milk accounting.

\section{Materials and methods}

Consider a simplified model of a capacitive flow sensor during the passage of milk through it, Fig. 1. The sensor has a rectangular cross section with the height $h_{s}$, width $a_{s}$, cross-sectional area $S_{s}$ and the length $L_{s}$. In the process of operation, portions of milk in the length $L_{m}$ with velocity $V_{m}$ pass through the sensor in the cork mode.

The volume of milk obtained during a milking session is determined by the following:

$$
W_{m}=S_{s} \times \sum L_{m, i},
$$

where $W_{m}$-volume of milk, $\mathrm{m}^{3}$;

$S_{S}$ - cross-sectional area of the sensor, $\mathrm{m}^{2}$; 
$\sum L_{m, i}-$ total length of portions of milk that passed through the sensor during milking, $\mathrm{m}$.

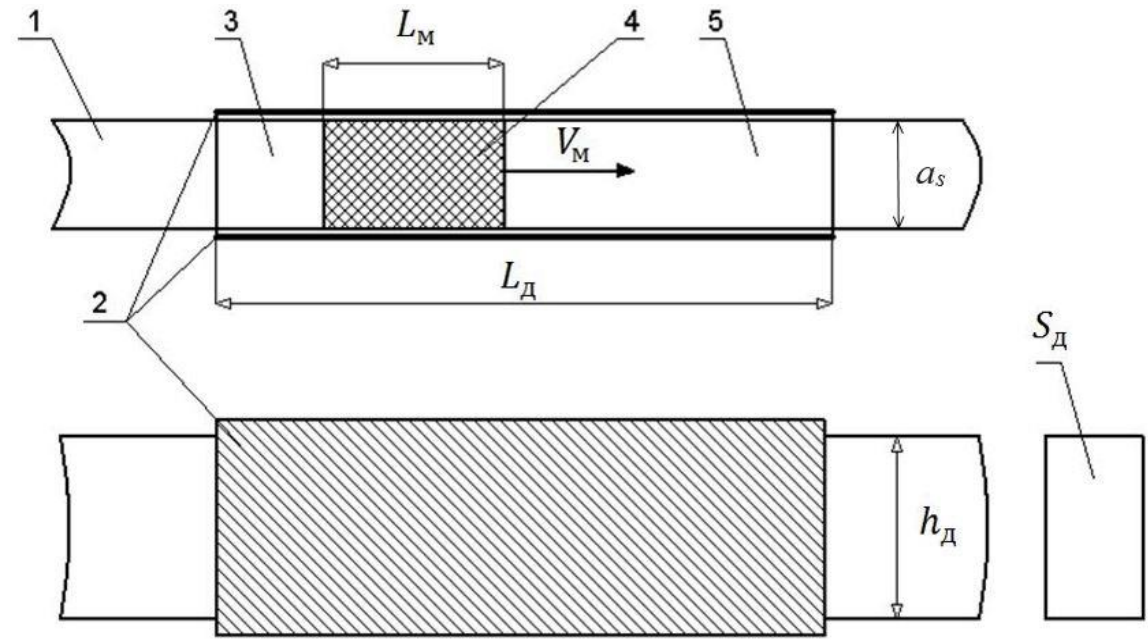

Fig. 1. Scheme of the capacitive flow sensor: 1 - milk hose of the milking machine; 2 - outer part of the sensor; 3 - part of the sensor moistened with a portion of milk; 4 - milk-filled part of the sensor;

5 - part of the sensor moistened with a preliminary portion of milk; $L_{s}$ - length of the sensor;

$h_{s}$ - height of the sensor; $L_{m}$ - length of the milk stopper; $a_{s}$ - width of the milk stopper; $V_{m}$ - milk velocity vector; $S_{s}$ - cross-sectional area of the sensor

To determine the length of a portion milk, you need to establish how the sensor signal changes during its passage. The task is complicated by the fact that the signal of the sensor moistened with milk after passing the next portion of milk significantly differs from the signal of an empty, non-wet sensor.

Therefore, the sensor output signal in general should be considered as the sum of the signals of its individual parts Fig. 1:

$$
F_{s}=F_{m}+F_{n p}+F_{o p},
$$

where $F_{S}$ - sensor output signal;

$F_{m}$ - signal of the sensor occupied by milk;

$F_{n p}$ - signal of the sensor behind the next portion of milk (new film);

$F_{o p}$ - signal of the sensor in front of the next portion of milk (old film).

Portions of milk can be shorter or longer than the length of the sensor covers. The signal of a short milk portion is determined by:

$$
F_{s}^{s h}=k_{s} h_{s} L_{s h}
$$

where $F_{s}^{s h}$ - short milk plug signal;

$k_{s}$ - sensor sensitivity;

$h_{s}$ - height of the sensor walls, m;

$L_{s h}-$ length of the short portion of milk, m.

The signal for a long milk portion corresponds to the maximum possible level of the sensor signal and is determined by the relationship:

$$
F_{S}^{L}=F_{s}^{\max }=k_{s} h_{s} L_{l},
$$

where $F_{S}^{L}-$ long milk plug signal;

$F_{S}^{\max }$ - maximum possible sensor signal;

$L_{l}-$ length of the long portion of milk, $\mathrm{m}$.

A sensor that is completely filled with milk has the highest signal level, because it has the highest capacitance and the lowest dielectric loss compared to the signal of milk foam and milk film.

Let us consider the dynamics of the signal of a sensor moistened with milk (milk film) in the absence of foam, Fig. 2. 


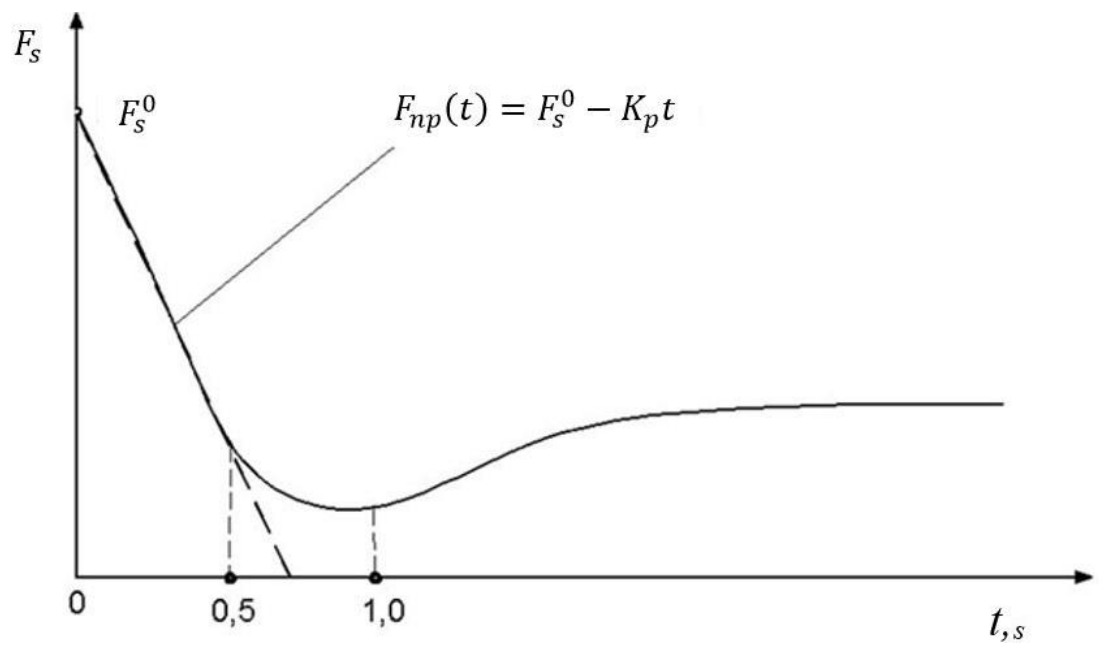

Fig. 2. Dynamics of the signal of the capacitive flow sensor moistened with milk after passing the previous portion of milk (signal from the milk film on the walls of the sensor)

At the moment of time, another portion of milk passed through the sensor, a milk film formed on its walls. The sensor signal at a time interval from $0 \mathrm{sec}$. to about $0.5 \mathrm{sec}$. can be interpolated by a linear function. Taking into account the frequency of operation of the pulsator of modern milking machines during milking, the milk film on the walls of the sensor exists within the above time interval and is determined by the dependence:

$$
F_{n p}(t)=F_{s}^{0}-K_{p} t
$$

where $F_{S}^{0}$ - sensor signal at time $t=0$;

$K_{p}$ - coefficient of proportionality.

The specific values of the interpolation coefficients depend on the material of the sensor body, the conductivity of the milk, the operating pressure in the milk line, and the temperature. At the same time, provided that the interpolation coefficients are determined immediately during milking before the arrival of each milk plug, the influence of these factors is significantly weakened.

Consider the process of passing milk portions through a capacitive sensor, provided that the speed of the milk portion at the moment of passing through the sensor is constant. The sensor has a rectangular cross-section, the milk plug has the shape of a parallelepiped, and its edges are orthogonal to the sensor walls, the sensor was instantly moistened with milk at time $t_{1}$ until the next milk plug approaches.

Consider the case of a short milk portion passing through the sensor, Fig. 3.

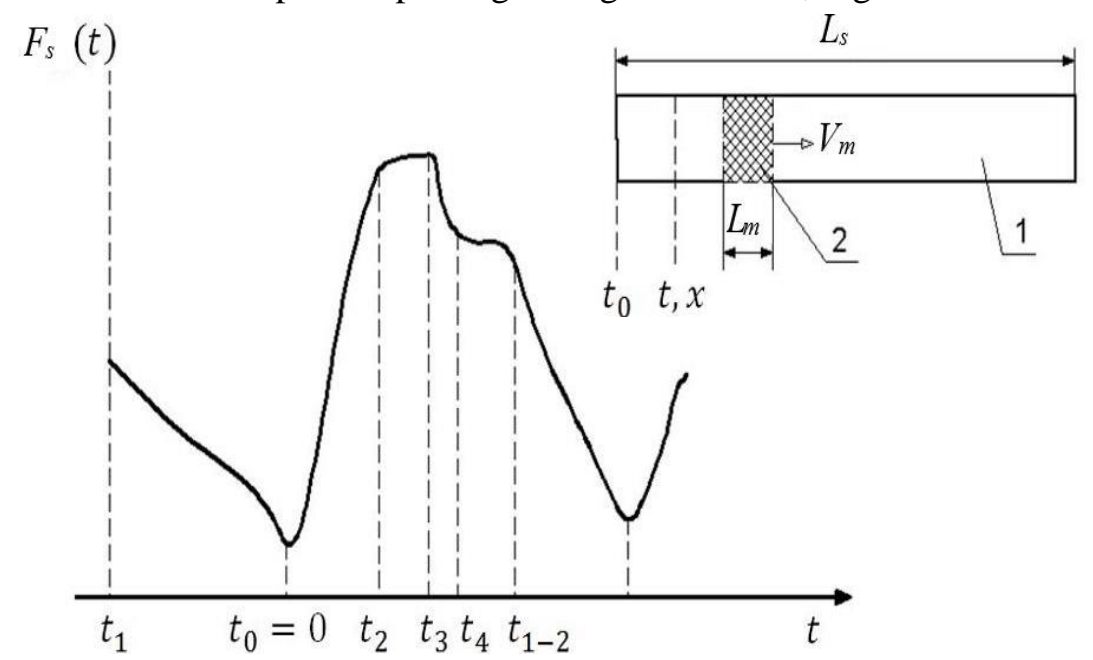

Fig. 3. Dynamics of the signal of the capacitive flow sensor when milk plugs pass through it:

1 - sensor; 2 - milk plug; $L_{m}$ - length of the milk plug; $V_{m}$ - speed;

$t_{0}, t_{1}, t_{2}, t_{3}, t_{4}, t_{1-2}$ - characteristic moments of time 
At time $t_{-1}$, the previous milk portion passed through the sensor - the process of collecting (relaxation) the milk film began. At the moment of time $t_{-0}$, the next portion of milk came to the entrance to the sensor. At time $t_{-2}$, the portion of milk has completely entered the sensor, in which case a signal is observed, which is the sum of signals from the milk portion and the film from the portion of milk. At time $t_{-3}$, the milk portion has approached the sensor exit, and the sensor signal is the sum of the signals from the milk plug and the film formed by it. At time $t_{-4}$, the milk portion has left the sensor, and the signal is formed by the influence of milk residues, milk foam and again the film. From time $t_{-1-2}$ the cycle of the sensor is repeated, it receives the next portion of milk.

Let us reveal the components of the signal of the capacitive flow sensor, when a short milk portion passes through it in accordance with the relationship (2):

$$
\begin{gathered}
F_{s}^{s h}(t)=F_{m}(t)+F_{n p}(t)+F_{o p}(t), \\
F_{n p}(t)=\int_{0}^{x 1-L_{m}}\left(k_{0}-k \frac{x 1-L_{m}-x}{V_{m}}\right) h_{s} d x, \\
F_{o p}(t)=\left(k_{0}-k t\right) \times\left(S_{s}-V_{m} h_{s} t\right),
\end{gathered}
$$

where $F_{S}^{s h}(t)$ - sensor signal when passing a short milk plug;

$F_{m}(t)$ - signal of the sensor area occupied by milk;

$F_{n p}(t)$ - signal of the sensor area moistened with the next portion of milk;

$F_{o p}(t)$ - signal of the sensor area moistened with the previous portion of milk;

$k_{0}=F_{S}^{0} / S_{s}$ та $k=K_{\Pi} / S_{S}-$ specific coefficients;

$S_{S}$ - surface area of the sensor.

After integration, substitution of components and replacement of $x=V_{m} t$, dependence (6) will take the form:

$$
\begin{aligned}
F_{s}^{s h}(t)=h_{s}\left(V_{m} t\right. & \left.-L_{m}\right) \times\left[k_{0}-\frac{k}{2}\left(t-\frac{L_{m}}{V_{m}}\right)\right]+\left[k_{0}-k\left(t_{1}+t\right)\right] \times \\
\times & {\left[1-\frac{t \times V_{m}}{L_{s}}\right] \times S_{s}+k_{s} L_{m} h_{s}, }
\end{aligned}
$$

Provided that at the moment of determining the length of a short milk portion, the next portion of milk has completely entered the sensor, and the film formed by it has not yet spread in time $t_{2}$, Fig. 3 , we obtain a dependence for determining the length of short portions:

$$
L_{m}^{s h}=\frac{F_{s}^{s h}-F_{o p}\left(t_{1}+t_{2}\right)}{F_{s}^{\max }-F_{o p}\left(t_{1}+t_{2}\right)} \times L_{\text {д }} .
$$

When a long milk plug passes through the sensor, its volume is completely filled with milk, and the signal reaches its maximum value, it becomes impossible to determine the portion length using equation (10). To determine the length of a portion of milk, it is enough to set the time of its entry and exit from the sensor, as well as the speed of the movement, Fig. 3:

$$
L_{m}^{L}=\left(t_{4}-t_{\mathrm{o}}\right) \times V_{m}^{L},
$$

Taking into account the principle of operation of a flow-through sensor of a capacitive type, the speed of a long milk portion is proportional to the rate of rise the sensor signal from its value at time $t_{\mathrm{o}}$ to the maximum signal value at the moment of its full filling with milk and it is determined from the dependence:

$$
V_{m}^{L}=L_{s} / t_{2} \text {. }
$$

\section{Results and discussion}

On the basis of the developed method in NSC "IAEE", the automatic milk meter of individual milking is created, Fig. 4. A study of its accuracy during milking in the stall milk duct, Fig. 5, and laboratory studies of the meter in the system of the installation for milking cows in the stall, Fig. 6, are performed.

The research was conducted in the farm of Kyiv region. Control measurements in production conditions were carried out on two tie stall farms. Each farm had 100 animals. The total number of 
control milking was 30 repetitions. Pipeline milking system was used. Cows have an average productivity of 6 thousand litters of milk, average fat content of $4.1 \%$. Three milking machines with installed meters were used. The test milk meter was installed in the milk hose. For the best results, a milk meter was installed in the upper part of the milk supply hose, so that the milk flow passed from top to bottom. Tests of the milk meter were also performed in the laboratory. Production tests were compared with laboratory tests. A production test was also carried out in a milking parlour with a lower milk line.
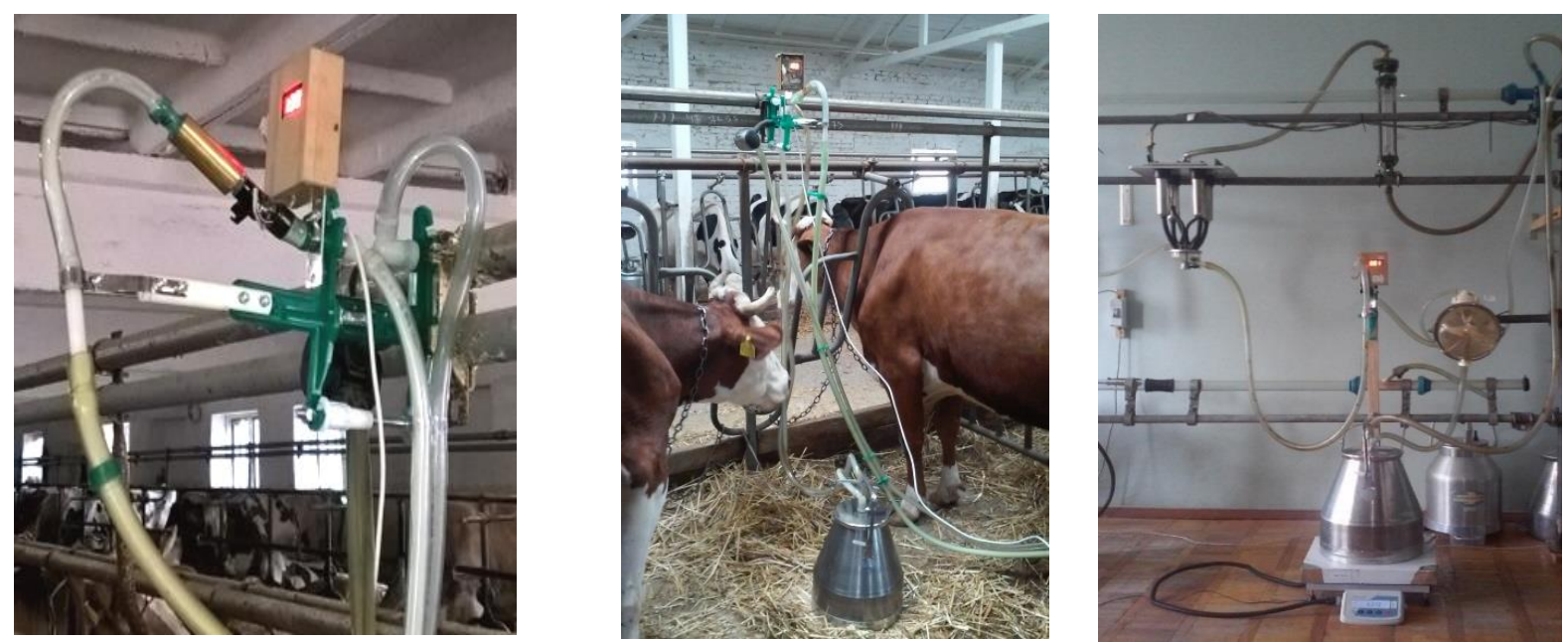

Fig. 4. Prototype of an automatic individual milk yield meter based on a capacitive flow sensor for industrial and laboratory research

The average measurement error during milking of low-yielding livestock in production conditions (tie-stall barn keeping, pipeline milk system) was 5.7\%, Fig. 5.

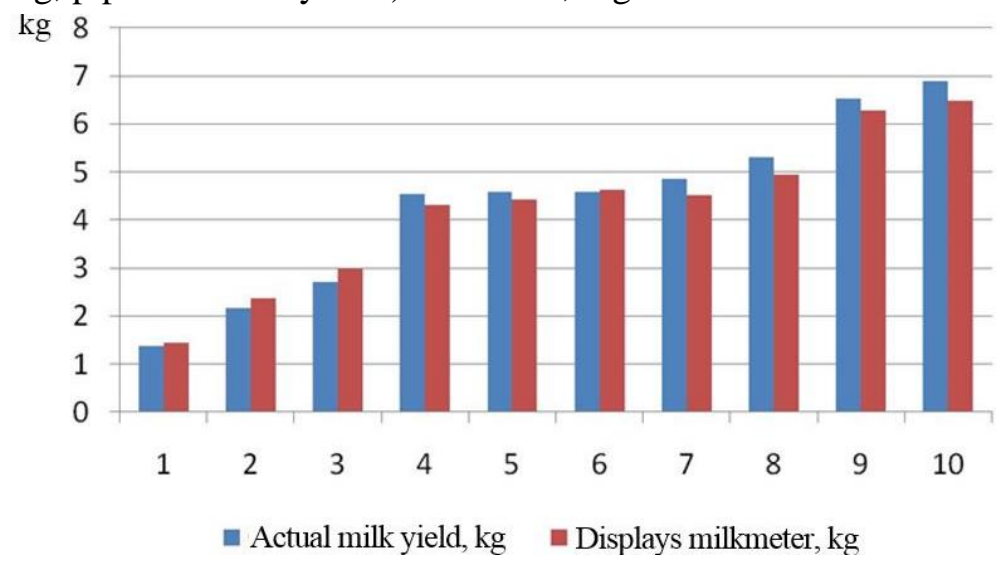

Fig. 5. Comparison of the actual milk yield and displays of the milk meter during milking in a stall milk pipeline under production conditions

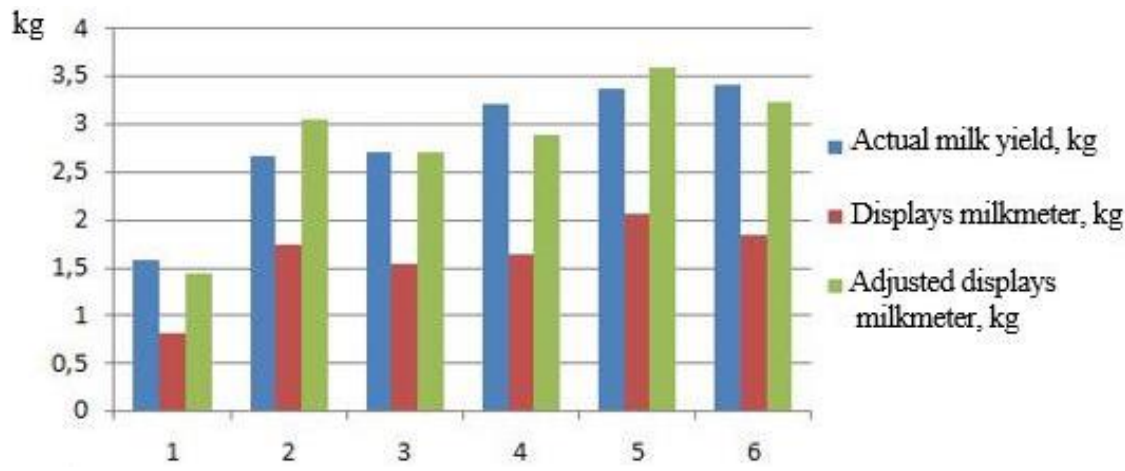

Fig. 6. Comparison of the actual milk yield and displays of the milk meter during milking in the milking parlour with a lower milk line under laboratory conditions:

intensity of milk production $4.16 \times 10^{-5} \mathrm{~m}^{3} \cdot \mathrm{s}^{-1}$ 
During laboratory studies, a systematic deviation of the meter readings to the lower side was recorded, Fig. 6, due to the use of the lower milk pipe to simulate the milking parlour. A systematic dependence of the meter readings on the intensity of milk production was also established. The specified systematic deviation is corrected by introducing a correction factor, which, if the intensity of milk production changes from $1.6 \times 10^{-5} \mathrm{~m}^{3} \cdot \mathrm{s}^{-1}$ to $6.6 \times 10^{-5} \mathrm{~m}^{3} \cdot \mathrm{s}^{-1}$, changes from 1.2 to 1.75 , respectively. The use of certain correction factors ensures sufficient measurement accuracy both for installations with stall milk pipelines and for milking parlours, including during milking of high-performance cows.

\section{Conclusions}

1. The obtained mathematical model of the flow rate of a pulsating milk flow based on the analysis of the signal of the capacitive flow sensor made it possible to create a milk meter for a milking machine.

2. Under the conditions of the developed mathematical model, the result of calculating the amount of milk does not depend on the characteristics of the capacitive flow sensor, and, consequently, on the electrical properties of milk.

3. An automatic meter of individual milk yield has been created, which ensures sufficient measurement accuracy in milking installations in stalls and in a milking parlour.

4. The average measurement error when milking low-yielding livestock in production conditions was $5.7 \%$. There is also a systematic dependence of meter readings on the intensity of the milk production. These systematic deviations are corrected by the introduction of a correction factor, which, when changing the intensity of milk production from $1.6 \times 10^{-5} \mathrm{~m}^{3} \cdot \mathrm{s}^{-1}$ to $6.6 \times 10^{-5} \mathrm{~m}^{3} \cdot \mathrm{s}^{-1}$, changes from 1.2 to 1.7 , respectively.

\section{References}

[1] Medvedskyi O., Kukharets S., Cesna J., Achkevych V. Estimation of mechanical and technological specifications of milk transporting system of milking machine. Engineering for rural development, Jelgava, 2020, pp. 1456-1462.

[2] Achkevych O., Achkevych V., Bratishko V., Potapova S. Justification of rational design parameters of milking machine for installations with milk line system. Engineering for rural development, Jelgava, 2020, pp. 1313-1318.

[3] Акупиан А.Н. К вопросу обоснования конструкционных параметров счётчика молока. (On the issue of substantiating the design parameters of the milk meter). Достижения науки и техники АПК №12, 2008, ст. 56-58. (In Russian).

[4] Milking Automation Technologies. [online] [15.12.2020]. Available at: https://www.allflex.global/milking-automation-technologies

[5] BECO Dairy Automation. [online] [21.01.2021]. Available at: https://www.becoknows.com/automation

[6] Zhu X., Guo W., Jia Y. Dielectric Properties of Raw Milk as Functions of Protein Content and Temperature. Food and Bioprocess Technology. 2015. No. 8. 670 p.

[7] Andreen D., Salfer I., Ying Y., Reinemann D. Method for improving precision of in-parlor milk meters and adjusting milk weights for stall effects. Journal of Dairy Science, vol. 103, 2020, pp. 5162-5169.

[8] Penry J., Leonardi S., Upton J., Thompson P., Reinemann D. Assessing liner performance using on-farm milk meters. Journal of Dairy Science, vol. 99, issue 8, 2016, pp. 6609-6618.

[9] Hongliang Q., Pega H. Characterization of R134a two-phase flow regimes in horizontal and vertical smooth tubes with capacitive sensors. International Journal of Refrigeration, vol.125, May 2021, pp. 90-103.

[10] Адамчук В., Фененко А., Братишко В., Ткач В. Механизация и автоматизация производства молока. Нежин, 2013. 324 с. (In Russian).

[11] Arshak P., Hanno G., Michael J. Rapid methods and sensors for milk quality monitoring and spoilage detection. Biosensors and Bioelectronics, vol.140, September 2019, pp. 117- 132.

[12] Steinfeld L. Inline mastitis detection system measuring the electrical conductivity of quarter milk. Conference: 2020 IEEE International Conference on Industrial Technology (ICIT). Available at: https://www.researchgate.net/publication/340696122_Inline_mastitis 